\title{
Role of computed tomography in determining the choice of treatment for delayed ceramic acetabular liner fracture: A case report
}

\author{
Ferdi Dırvar \\ Department of Orthopedics and Traumatology, Metin Sabancı Baltalimanı Bone Diseases Training and Research Hospital, Istanbul, Turkey
}

The fracture rate of ceramic components has been reported to be between $0.013 \%$ and $1.1 \%$ for acetabular liners. ${ }^{[1,2]}$ Based on the available data, the revision operation after a ceramic component fracture should be performed as soon as possible to avoid spreading of ceramic particles. Revision to metal on polyethylene bearing surface may be considered a salvage option only if thorough synovectomy and pulsatile lavage are performed. ${ }^{[3]}$ The fragments of the failed component are sharp and harder than metal; if left in the articular space, these fragments would act as an abrasive paste, and the use of a metal head against a polyethylene liner in the revision arthroplasty would quickly lead to catastrophic wear and failure of these new total hip implants. ${ }^{[4,5]}$ The explanation lies in better tribological behavior of the ceramics, particularly high resistance of ceramics to third body wear. ${ }^{[6]}$ At present, there is no consensus on the best bearing surface for revision following fracture of the ceramic component. ${ }^{[3,7]}$

Computed tomography (CT) has been suggested if plain radiographs are not diagnostic and there is still suspicion of a ceramic bearing fracture. ${ }^{[8]}$ In this case report, we used CT to detect the location of the ceramic fragments. We acquired this information to

Received: November 07, 2019

Accepted: January 11, 2020

Published online: June 18, 2020

Correspondence: Ferdi Dırvar, MD. Metin Sabancı Baltalimanı Kemik Hastalıkları Eğitim ve Araştırma Hastanesi Ortopedi ve Travmataloji Kliniği, 34470 Sarıyer, İstanbul, Türkiye.

E-mail: ferdidirvar@hotmail.com

Doi: $10.5606 /$ ehc. 2020.72241

Citation: Dirvar F. Role of computed tomography in determining the choice of treatment for delayed ceramic acetabular liner fracture: A case report. Jt Dis Relat Surg 2020;31(2):377-381.

\section{ABSTRACT}

Ceramic acetabular liner fracture is a rare complication and requires early revision surgery to avoid abrasive damaging of metal components by ceramic particles. Chromium-cobalt femoral head can be used in revision surgery if only fractured ceramic particles are completely removed because the abrasive effect of ceramic debris is more pronounced on metal head compared to ceramic head. In this article, we report a 50-year-old male patient of delayed acetabular liner fracture in which we used a ceramic head that is more resistant to residue ceramic particles. We assessed the patient by using computed tomography (CT) to locate the ceramic particles. By using CT imaging, we can detect which ceramic particles pose high morbidity risk for debridement.

Keywords: Ceramic liner fracture, computed tomography, metallosis, total hip arthroplasty.

evaluate which particles we could reach by thorough synovectomy and this preoperative planning helped us in deciding on our implant choice..$^{[9]}$

\section{CASE REPORT}

A 50-year-old male patient was admitted with complaint of pain at the right hip and also limb length shortening. A total right hip prosthesis had been applied in 2012 in another medical center. Patient had a traumatic event in 2014 and after examination and a proper X-ray imaging, acetabular liner fracture was diagnosed. Patient refused the choice of revision hip arthroplasty and continued full weight bearing for three years. In 2017, the patient was accepted to our hospital whose pelvis anteroposterior X-ray visualized a catastrophic acetabular component failure (Figure 1). A written informed consent was obtained from the patient.

On right hip CT imaging at bone window (window level 800 Hounsfield unit [HU] and width 2,400 HU), 
there were high-density amorphous morphological sites without clear borders which began within the iliacus muscle at proximal border, continuing within iliopsoas muscle till its distal tendon beginning anterior to hip joint, and advancing to rectus femoris
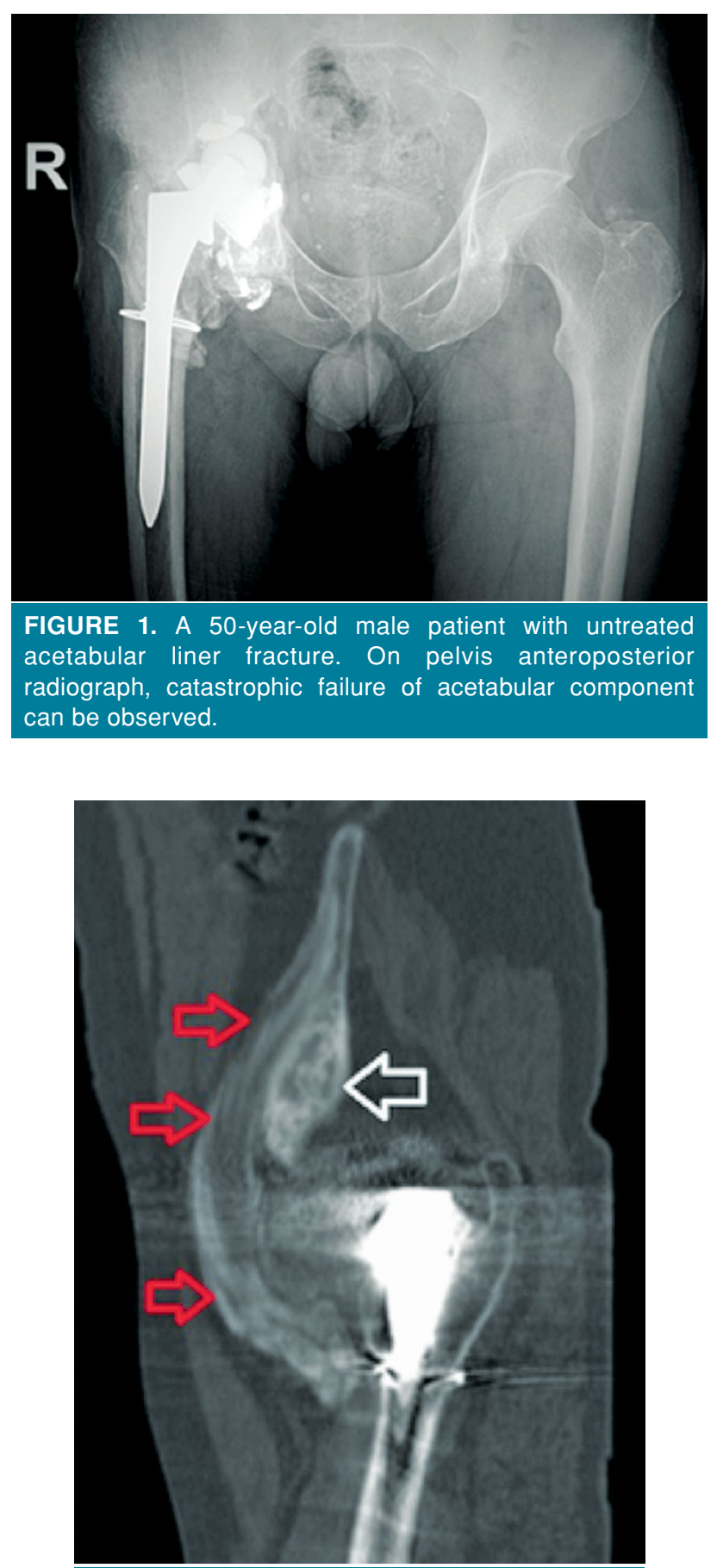

FIGURE 2. Metallosis distribution in iliacus muscle (red arrows) and iliac bone (white arrow) in periacetabular region is demonstrated on sagittal computed tomography image. muscle's proximal portion neighboring to iliopsoas muscle's distal portion. Same high-density amorphous morphological sites were visualized inside the iliac bone at periacetabular region (Figure 2). We evaluated these amorphous high-density sites with patient's clinical information as metallosis components. On CT images, we applied "whiting out" (window level 2,500 HU and width 7,000 HU); then, tissues affected by metallosis became less visible while ceramic fragments could be seen more clearly (Figure 3). We detected an oval defect at the superomedial portion of the acetabular shell and femoral head protrusion through acetabular shell component. Also, there were local resorption bone sites at the acetabular roof's medial and lateral contours. Through the resorption site, we could see the marked protrusion of the head of the prosthesis to iliac fossa. There were multiple high-signal-density particles $1 \mathrm{~cm}$ largest in size located at medial and inferior to right hip joint and at the acetabular roof and its medial border indicating ceramic fragments. Also, we could see the same highsignal-density millimetric particles anterior to right hip joint in less numbers (Figure 4).

At preoperative planning based on CT imaging, we concluded that it would not be possible to clean out all the ceramic debris particles safely. Thus we decided to use ceramic on ceramic bearing surface revision hip
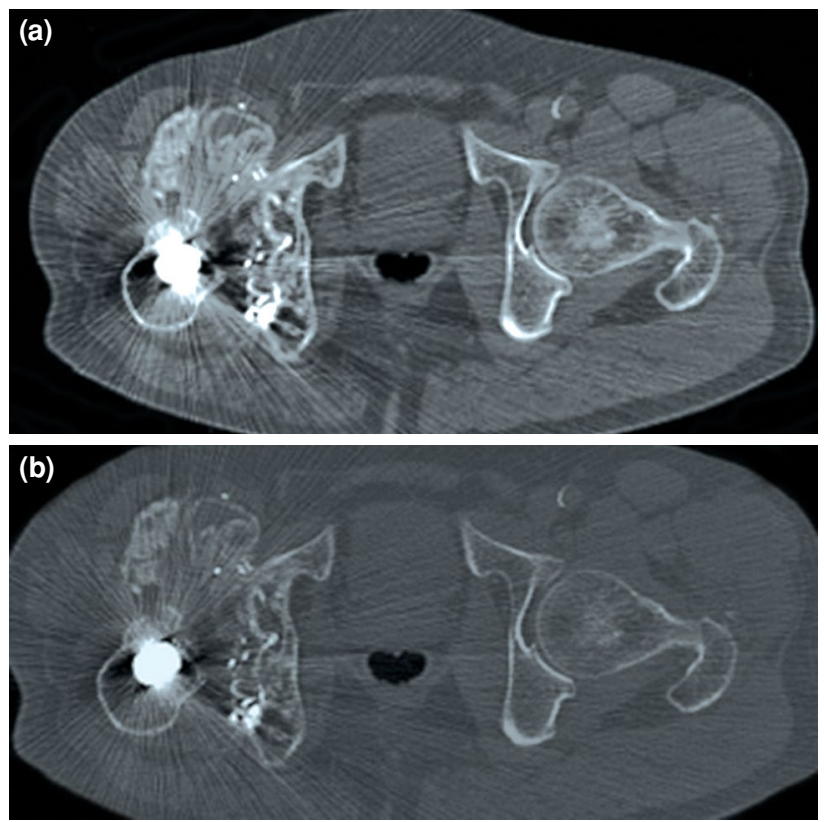

FIGURE 3. (a) Amorphous high-density sites can be observed on rectus femoris muscle's proximal portion and hip joint space in axial views. (b) After application of whiting out technique, ceramic fragments can be seen more clearly on computed tomography image. 


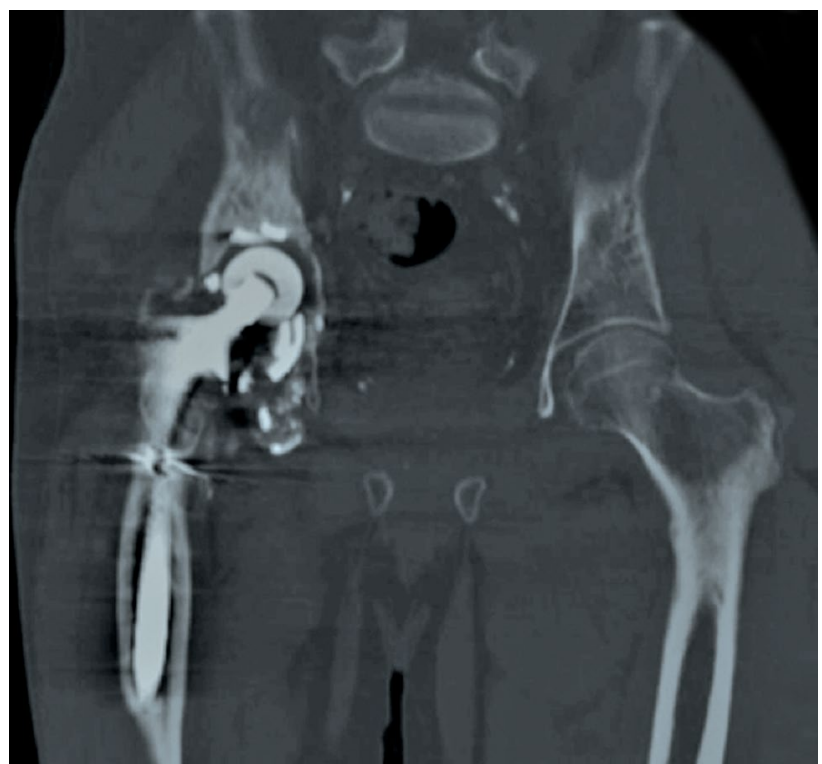

FIGURE 4. Femoral head protrusion through acetabular shell component is observed and ceramic fragments can be readily seen in acetabular roof region in coronal computed tomography image of right hip.

prosthesis which is much more resistant to ceramic debris. Use of extended trochanteric osteotomy led to effortless extraction of protruded femoral stem, then wide exposure for acetabular shell extraction, after enabling the hip joint to be more reachable for debridement of metallosis and ceramic fragments
(Figure 5). Reconstruction was performed with medial acetabular defect allograft grafting, PINNACLE ${ }^{\circledR}$ acetabular $56 \mathrm{~mm}$ multihole revision cup with two cancellous acetabular screws (Depuy, Warsaw, IN, USA), and BIOLOX ${ }^{\circledR}$ delta ceramic acetabular liner (CeramTec GmbH, Plochingen, Germany). Femoral side was reconstructed with long-stemmed extensively coated $13.5 \mathrm{~mm}$ cementless revision stem (Solution ${ }^{\mathrm{TM}}$ DePuy, Warsaw IN, USA), BIOLOX ${ }^{\circledR}$ delta $36 \mathrm{~mm}+1.5$ ceramic head, and extended trochanteric osteotomy fixation with Dall-Miles cable grip. Ceramic fragments were still present at early postoperative radiography (Figure 6). There was no indication for a postoperative control CT, as exact localization of ceramic fragments was not required for follow-up treatment.

Early postoperatively, patient was followed-up with non-weight bearing for six weeks followed by partial weight bearing between six and nine weeks continued with full weight bearing. There were no early postoperative complications.

At two-year follow-up examination, Harris hip score was $96.65 \%$ with no evidence of osteolysis or implant deformity (Figure 7).

\section{DISCUSSION}

Of all bearing surface options for total hip revision replacement at ceramic liner fracture, polyethylene on metal can be used if a complete and thorough synovectomy can be performed. For appropriate
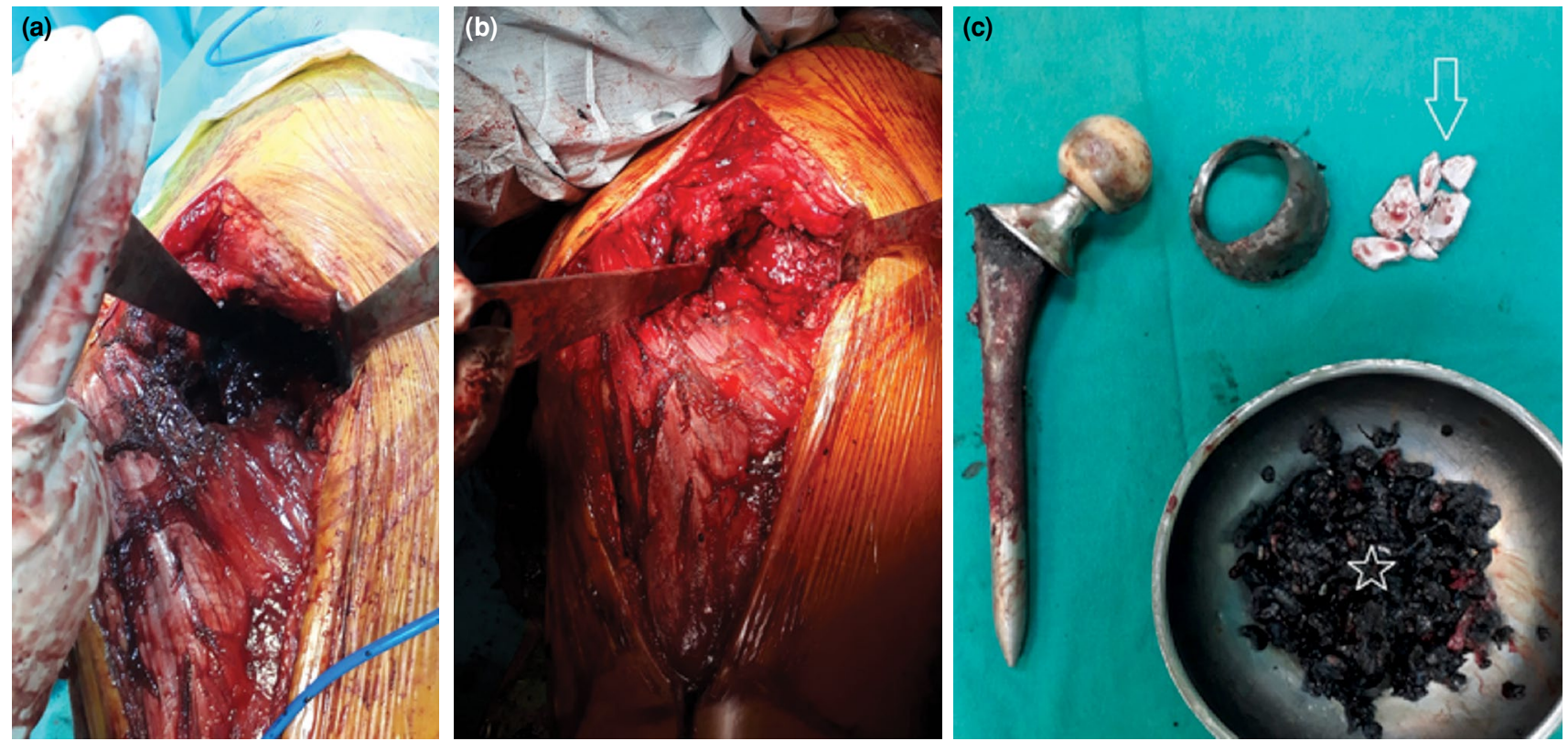

FIGURE 5. (a) Hip joint view before debridement. (b) Hip joint view after debridement and implant extraction. (c) Extracted implants, debrided metallosis tissue (white star), and fractured ceramic fragments (white arrow) are shown. 


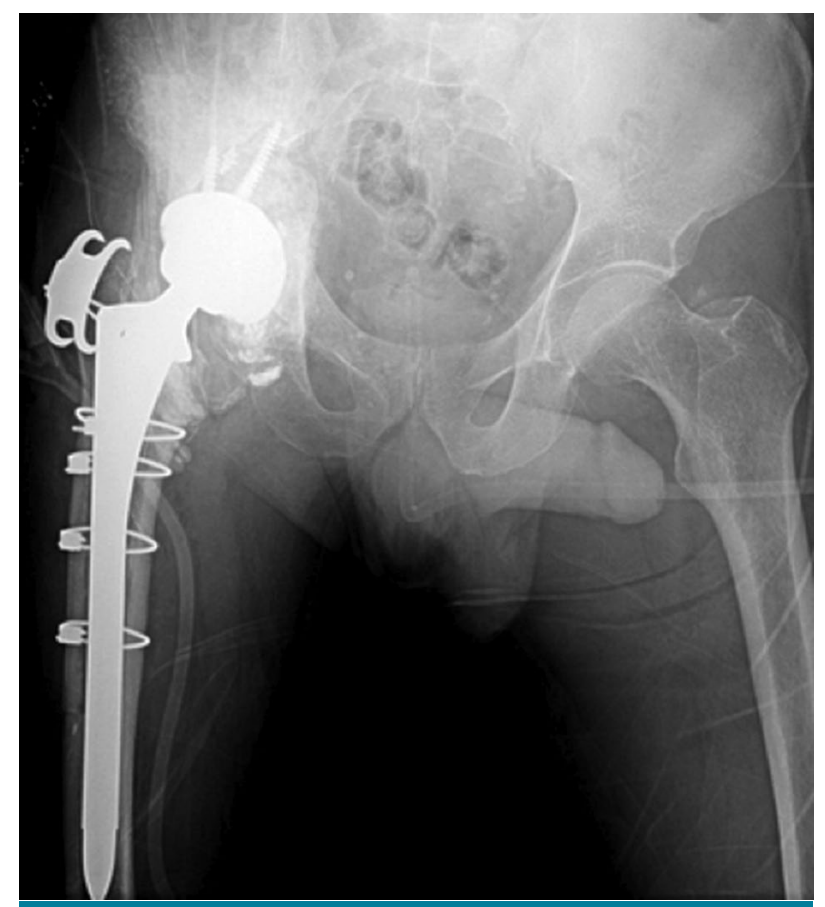

FIGURE 6. Right hip metallosis and ceramic fragments inferior to acetabular component are still present on early postoperative pelvis anteroposterior radiography.

synovectomy, extensive exposure for entire pseudocapsule and synovium excision technique have been described. ${ }^{[3]}$ However, in massive metallosis due to ceramic fracture, even with extensive debridement, the pelvis cannot be cleaned safely from metallosis and ceramic fragments. ${ }^{[10]}$

Likewise, in this case, even though using extended trochanteric osteotomy to gain greater exposure for hip joint even though we used extended trochanteric osteotomy to gain greater exposure for hip joint, because some of the ceramic fragments were at highly risky anatomic locations, we ended the operation without cleaning up all the ceramic fragments.

To remove all the fractured ceramic fragments, the principles of tumor surgery would have to be applied. Since it is impractical to enforce this requirement in revision endoprosthetics, it should always be expected that ceramic particles would remain in situ. ${ }^{[4]}$

X-ray images prior to the revision surgery are used to show the position of fractured components. ${ }^{[1]}$ However, plain X-ray imaging is not sufficient for delayed acetabular liner fractures since particles might spread until the time of diagnosis. For avoiding misinterpretation and detecting the exact locations of the particles at the hip joint, we need

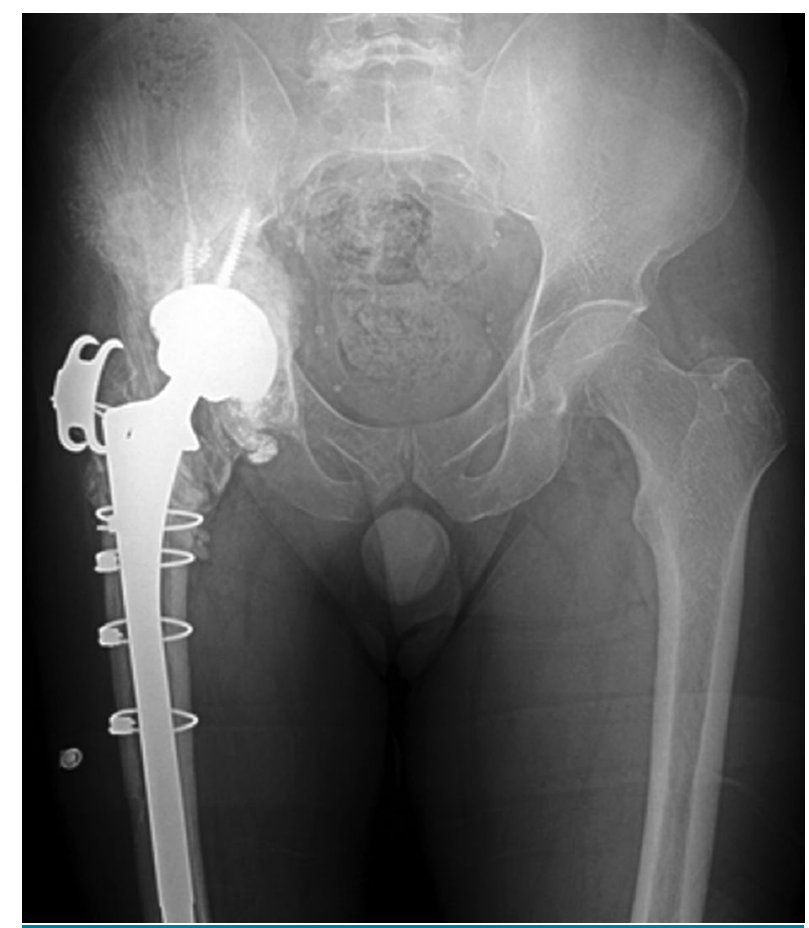

FIGURE 7. Follow-up pelvis anteroposterior radiograph two years after revision total hip arthroplasty. assistance from three-dimensional imaging like CT. Computed tomography scan can be used for early diagnosis at occult ceramic liner fractures, ${ }^{[12]}$ contemporarily to ascertain the presence of ceramic fragments eventually not visible with traditional X-ray. ${ }^{[6]}$ Also, CT can show concomitant bone defects around the implants. ${ }^{[13]}$ Computed tomography scan at the standard "bone window" can mask the visualization of ceramic fracture fragments, while "whiting out" technique decreases the streak artifact from the hyperdense titanium and less dense ceramic fragments can be visualized. ${ }^{[14]}$ In this case, we used the whiting out technique to decrease the high-signal density caused by metallosis. Ceramic particles are more easily identified on CT images. This gives us the possibility to establish a more realistic preoperative planning.

In conclusion, in delayed cases, the ceramic particles that are deposited in periarticular tissues can be detected with the help of CT, which helps in planning the extent of the surgical debridement area and the choice of the bearing surface to be used.

\section{Acknowledgements}

I would like to thank Mustafa Cantay Gok, M.D., for his input in the discussion on radiology results. 


\section{Declaration of conflicting interests}

The author declared no conflicts of interest with respect to the authorship and/or publication of this article.

\section{Funding}

The author received no financial support for the research and/or authorship of this article.

\section{REFERENCES}

1. D'Antonio JA, Sutton K. Ceramic materials as bearing surfaces for total hip arthroplasty. J Am Acad Orthop Surg 2009;17:63-8

2. Hamilton WG, McAuley JP, Dennis DA, Murphy JA, Blumenfeld TJ, Politi J. THA with Delta ceramic on ceramic: results of a multicenter investigational device exemption trial. Clin Orthop Relat Res 2010;468:358-66.

3. Sharma V, Ranawat AS, Rasquinha VJ, Weiskopf J, Howard H, Ranawat CS. Revision total hip arthroplasty for ceramic head fracture: a long-term follow-up. J Arthroplasty 2010;25:342-7.

4. Matziolis G, Perka C, Disch A. Massive metallosis after revision of a fractured ceramic head onto a metal head. Arch Orthop Trauma Surg 2003;123:48-50.

5. Allain J, Roudot-Thoraval F, Delecrin J, Anract P, Migaud H, Goutallier D. Revision total hip arthroplasty performed after fracture of a ceramic femoral head. A multicenter survivorship study. J Bone Joint Surg [Am] 2003;85:825-30.

6. Traina F, De Fine M, Di Martino A, Faldini C. Fracture of ceramic bearing surfaces following total hip replacement: a systematic review. Biomed Res Int 2013;2013:157247.

7. Lee SJ, Kwak HS, Yoo JJ, Kim HJ. Bearing Change to MetalOn-Polyethylene for Ceramic Bearing Fracture in Total Hip Arthroplasty; Does It Work? J Arthroplasty 2016;31:204-8.

8. Traina F, Tassinari E, De Fine M, Bordini B, Toni A. Revision of ceramic hip replacements for fracture of a ceramic component: AAOS exhibit selection. J Bone Joint Surg [Am] 2011;93:e147.

9. Atik OŞ. Which articles do we prefer to publish? Eklem Hastalik Cerrahisi 2018;29:1.

10. Winston BA, Kagan RP, Huff TW. Delayed diagnosis of catastrophic ceramic liner failure with resultant pelvic discontinuity and massive metallosis. Arthroplast Today 2016;3:77-82.

11. Trebše R, Mihelič A, Levašič V, Cör A, Milošev I. Results of revision of total hip arthroplasty for alumina ceramic-onceramic bearing fracture. Hip Int 2016;26:237-43.

12. Trivellin G, Sandri A, Bizzotto N, Marino MA, Mezzari S, Sambugaro E, et al. Ceramic liner fatigue fracture: 3-D CT findings in a late recurrent THA dislocation. Orthopedics 2013;36:e101-4.

13. Takasago T, Goto T, Wada K, Hamada D, Iwame T, Matsuura T, et al. Metallosis after Exchange of the Femoral Head and Liner following Ceramic Acetabular Liner Dissociation in Total Hip Arthroplasty with a Modular Layered Acetabular Component. Case Rep Orthop 2016;2016:5301451.

14. Endo Y, Renner L, Schmidt-Braekling T, Mintz DN, Boettner F. Imaging of ceramic liner fractures in total hip arthroplasty: the value of CT. Skeletal Radiol 2015;44:1189-92. 